\title{
Performance differences among the intervals in forced-choice tasks
}

\author{
DAVID M. JOHNSON, CHARLES S. WATSON, and WILLIAM J. KELLY \\ The Boys' Town National Institute for Communication Disorders in Children, Omaha, Nebraska.
}

\begin{abstract}
Listeners were tested on a variety of three-interval, forced-choice auditory detection and discrimination tasks. Differences in performance were frequently found among the three intervals, with best performance in the third interval, and worst in the first. This result is at odds with the common assumptions of Signal Detection Theory that signals are equally detectable no matter which interval they are presented in, and that a decision is simply made by picking the interval with the largest likelihood ratio. An experimental technique is described by which central and peripheral determinants of the interval effect might be distinguished.
\end{abstract}

Multiple-interval forced-choice (MIFC) methods are often employed in auditory detection and discrimination tasks to avoid the effects of variation in response criterion. Two, three, four, or more observation intervals have been used. It has been suggested that when an MIFC procedure is used with equiprobable stimulus alternatives, subjects show only a relatively small bias in favor of one or another response alternative, tending instead to choose the presentation interval containing the most signal-like stimulus (Green \& Swets, 1966, p. 408). Formal models of MIFC performance have generally assumed uniformity of sensitivity across the $\mathrm{M}$ intervals for ease of calculation. However, it has been recognized that if an interval bias exists, it will always depress the overall percent correct (Green \& Swets, 1966, p. 409).

The issue of whether or not there are performance differences among the intervals of MIFC tasks has received very little attention. Watkins and Clark (1968) asked listeners to identify voices in a 4IFC task. They presented a sample stimulus of the target voice either at the beginning or at the end of the trial. The results showed percent correct per interval to deline monotonically with distance from the sample. These authors later examined interval-contingent performance using a signal detection task. Here, tones were presented in noise using the traditional 4IFC method, with no sample stimuli presented at the beginning or end of a trial. In this case, no statistically reliable differences in percent correct were

The research reported in this paper was supported by a grant from NIH/NINCDS to Charles S. Watson, and by a NIH fellowship to David M. Johnson. The comments of D. C. Foyle on an earlier version of this paper are gratefully acknowledged. D. $\mathbf{M}$. Johnson is now located at the U.S. Army Research Institute, Fort Bliss Field Unit, P.O. Box 6057, Fort Bliss, TX 79916. The mailing address of The Boys' Town National Institute is: .555 North 30 Street, Omaha, NE 68131. noted among the intervals. Those who study auditory capability using modern psychophysical methods need to know whether sensitivity is uniform over the $M$ intervals of forced-choice tasks because of the widespread use of those techniques. The purpose of this paper is to document the existence of intervalspecific effects in a variety of detection and discrimination tasks.

If differential performance across intervals of MIFC tasks exists, it could arise from differential detectability or from differential response criteria; however, there is no simple way to distinguish between these explanations. ${ }^{1}$

Throughout this paper, we discuss the "interval effect," by which we generally mean the difference in performance between interval 1 and interval 3. This difference is used as an index of the effect and is not meant to suggest that the effect is necessarily linear in nature. We avoid the use of the term "interval bias" because differential performance over intervals may not be a simple bias (effect of interval-specific criteria, in the terminology of signal detection theory), but may also reflect actual differences in sensitivity to a signal when it is presented in the various intervals.

Interest in this issue originated because we noticed an interval effect in an experiment reported elsewhere (Watson, Kelly, \& Mellen, 1979). In brief, we found poorer overall performance under 3IFC than when a similar experiment had been done using a samedifferent method (Watson, Kelly, \& Wroton, 1976). We wondered whether the listeners were having trouble with the memory load of 3IFC, which might have resulted in degraded performance in the earlier intervals. An adaptive tracking procedure (Levitt, 1971) had been used to maintain overall performance at $71 \%$ correct. Upon reanalysis we found that performance for interval 1 was $61 \%$ correct, for interval 2 it was $70 \%$ correct, and for interval $3,82 \%$ correct. ${ }^{2}$ Therefore, data from another group of experi- 
ments were examined to seek additional evidence of this effect.

\section{METHOD}

Sixteen listeners were paid to participate in this experiment. Listeners, most of whom were university students, ranged in age from 14 to 35 years. One listener had a slight hearing loss (15$20 \mathrm{~dB}$ ) in the midfrequency range in her right ear, all other listeners had audiometrically normal hearing. All listening was done monaurally with the right ear.

The 22 psychophysical tasks employed in this experiment were conducted as part of a project on individual differences in auditory capabilities (Johnson, Jensen, \& Watson, 1980). Table 1 lists values for specific stimulus parameters. Masked thresholds were determined for three frequencies $(250 \mathrm{~Hz}, 1 \mathrm{kHz}, 4 \mathrm{kHz})$. Quiet thresholds were measured at two stimulus durations (250 and $25 \mathrm{msec}$ ) for $1-\mathrm{kHz}$ tones. Intensity discrimination for $1-\mathrm{kHz}$ tones was tested at two stimulus durations ( 250 and $50 \mathrm{msec}$ ). Frequency discrimination was measured at three tone frequencies $(250 \mathrm{~Hz}$, $1 \mathrm{kHz}, 4 \mathrm{kHz}$ ) and two durations (50 $\mathrm{msec}$ and $200 \mathrm{msec}$ ). Discrimination of tone duration was measured at three frequencies $(250 \mathrm{~Hz}, 1 \mathrm{kHz}, 4 \mathrm{kHz})$ and two durations $(25$ and $200 \mathrm{msec})$. The discrimination of silent gaps bounded by noise bursts was tested at two gap durations ( 100 and $25 \mathrm{msec}$ ). The discrimination of increments in the duration of click trains was measured at three click rates $(14 / \mathrm{sec}, 28 / \mathrm{sec}, 56 / \mathrm{sec})$. The standard duration of the click train was $500 \mathrm{msec}$. Finally, the discrimination of temporal order was tested in two four-tone-sequence tasks in which the order of the two middle tones was varied. In one of the temporal-order tasks, the independent variable was the duration of the tones; in the other, it was the duration of the intertone interval.

Each of the 22 discrimination tasks was structured as a 3IFC procedure. That is, a listener was presented with three successive observation intervals in every trial. Two of these intervals contained a standard stimulus and the third, a variable stimulus. The interval that contained the variable stimulus changed randomly from trial to trial. Thus, the listener's job was to pick which interval contained the "odd" or "different" stimulus. How a stimulus was made to differ from its two standard companions was the independent variable. For example, during duration discrimination, the listener's task was to choose the interval that contained the longest stimulus. Listeners were given instructions as to how the stimuli would vary on each task. Suprathreshold examples were given before each task. Every listener reported understanding the task before data collection was begun.

Observation intervals were marked by lights on a response box, and were separated by 500 msec (the "interstimulus interval"). Listeners identified their choice of interval by pushing one of three buttons on the response box. Feedback was provided by lights above the response buttons. Trials were self-paced. An adaptive threshold tracking procedure (Levitt, 1971) was used to determine the value of the independent variable on each trial. The stepping rule chosen was two down/one up. That is, the value of the independent variable was reduced (made more difficult) after two correct responses in a row, and increased (made easier) after one incorrect response. This rule yields a stimulus history, or "track," that converges on the level associated with $71 \%$ correct performance. Two tracks were collected from each listener for all tasks. A running $t$ test was performed on the values of the independent variable for the previous $4 \mathrm{~min}$ worth of the stimulus history. This $t$ test compared the values of the independent variable produced during the first 2 min with those produced during the second $2 \mathrm{~min}$. If the null hypothesis of no difference could not be rejected (at the $10 \%$ level), the track was automatically terminated. Only trials from this "flat" or asymptotic portion of the second track were used in the calculation of proportion correct per interval.

Sinuosidal signals were generated by a Tektronix FG501 function generator. Frequency was controlled by a 12-bit digital-toanalog converter. During the frequency discrimination tests, all signals were produced digitally. Noise was produced by a GrasonStadler Model 1285 noise generator. The noise band was shaped by dual Ithaco $4302,24-\mathrm{dB} /$ octave filters. The signals were gated by Grason-Stadler 1287B electronic switches set to a rise/fall of

Table 1

Conditions of the Experiment

\begin{tabular}{|c|c|c|c|c|c|}
\hline Task & & Frequency & Signal Levels & Durations & Maximum Values \\
\hline $\begin{array}{l}\text { Masked } \\
\text { Thresholds }\end{array}$ & $\begin{array}{l}1 \\
2 \\
3\end{array}$ & $\begin{array}{r}250 \mathrm{~Hz} \\
1000 \mathrm{~Hz} \\
4000 \mathrm{~Hz}\end{array}$ & $\begin{array}{l}\text { Signal } 80 \text { dB SPL* } \\
\text { S/N } 50 \text { dB initially* }\end{array}$ & $\begin{array}{l}150 \mathrm{msec} \\
150 \mathrm{msec} \\
150 \mathrm{msec}\end{array}$ & $\mathrm{S} / \mathrm{N} 50 \mathrm{~dB}$ \\
\hline $\begin{array}{l}\text { Quiet } \\
\text { Thresholds }\end{array}$ & $\begin{array}{l}4 \\
5\end{array}$ & $\begin{array}{l}1000 \mathrm{~Hz} \\
1000 \mathrm{~Hz}\end{array}$ & $\begin{array}{l}60 \mathrm{~dB} \text { SPL initially* } \\
\text { reducing to }-10 \mathrm{~dB}^{*}\end{array}$ & $\begin{array}{r}250 \mathrm{msec} \\
25 \mathrm{msec}\end{array}$ & $60 \mathrm{~dB}$ \\
\hline Intensity & $\begin{array}{l}6 \\
7\end{array}$ & $\begin{array}{l}1000 \mathrm{~Hz} \\
1000 \mathrm{~Hz}\end{array}$ & $70 \mathrm{~dB}$ SPL* & $\begin{array}{r}250 \mathrm{msec} \\
50 \mathrm{msec}\end{array}$ & $\Delta \mathrm{I}=19 \mathrm{~dB}$ \\
\hline Frequency & $\begin{array}{r}8 \\
9 \\
10 \\
11\end{array}$ & $\begin{array}{r}1000 \mathrm{~Hz}^{*} \\
250 \mathrm{~Hz}^{*} \\
1000 \mathrm{~Hz}^{*} \\
4000 \mathrm{~Hz}^{*}\end{array}$ & $\begin{array}{l}60 \mathrm{~dB} \\
60 \mathrm{~dB} \\
60 \mathrm{~dB} \\
60 \mathrm{~dB}\end{array}$ & $\begin{array}{l}50 \mathrm{msec} \\
200 \mathrm{msec} \\
200 \mathrm{msec} \\
200 \mathrm{msec}\end{array}$ & $\Delta F=999 \mathrm{~Hz}$ \\
\hline $\begin{array}{l}\text { Tone } \\
\text { Duration }\end{array}$ & $\begin{array}{l}12 \\
13 \\
14 \\
15\end{array}$ & $\begin{array}{r}1000 \mathrm{~Hz} \\
250 \mathrm{~Hz} \\
1000 \mathrm{~Hz} \\
4000 \mathrm{~Hz}\end{array}$ & $\begin{array}{l}80 \mathrm{~dB} \\
80 \mathrm{~dB} \\
80 \mathrm{~dB} \\
80 \mathrm{~dB}\end{array}$ & $\begin{array}{l}25 \mathrm{msec}^{*} \\
200 \mathrm{msec}^{*} \\
200 \mathrm{msec}^{*} \\
200 \mathrm{msec}^{*}\end{array}$ & $\Delta T=300 \mathrm{msec}$ \\
\hline $\begin{array}{l}\text { Click- } \\
\text { Train } \\
\text { Duration }\end{array}$ & $\begin{array}{l}16 \\
17 \\
18\end{array}$ & (clicks) & $\begin{array}{l}40 \mathrm{~dB} \\
\text { Spectrum Level }\end{array}$ & $\begin{array}{l}100 \mu \mathrm{sec}, 14 / \mathrm{sec}, 500 \mathrm{msec}^{*} \\
100 \mu \mathrm{sec}, 28 / \mathrm{sec}, 500 \mathrm{msec}^{*} \\
100 \mu \mathrm{sec}, 56 / \mathrm{sec}, 500 \mathrm{msec}^{*}\end{array}$ & \\
\hline $\begin{array}{l}\text { Gap } \\
\text { Duration }\end{array}$ & $\begin{array}{l}19 \\
20\end{array}$ & $\begin{array}{l}\text { (noise) } \\
\text { (noise) }\end{array}$ & $\begin{array}{l}30 \mathrm{~dB} \\
\text { Spectrum Level }\end{array}$ & $\begin{array}{l}100 \mathrm{msec}^{*} \\
25 \mathrm{msec}^{*}\end{array}$ & $\Delta \mathrm{T}=300 \mathrm{msec}$ \\
\hline $\begin{array}{l}\text { 4-Tone } \\
\text { Sequence }\end{array}$ & $\begin{array}{l}21 \\
22\end{array}$ & 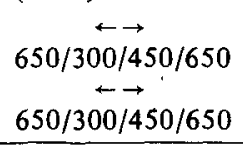 & $\begin{array}{l}80 \mathrm{~dB} \\
80 \mathrm{~dB} \\
\end{array}$ & $\begin{array}{l}\text { Gaps }=6-6-6 \\
\text { Tone }=100 / 1-300 / 1-300 / 100^{*} \\
\text { Gaps }=\text { all } 3-303^{*} \\
\text { Tone }=100 / 15 / 15 / 100\end{array}$ & $\begin{array}{l}300 \mathrm{msec} \\
303 \mathrm{msec}\end{array}$ \\
\hline
\end{tabular}

*Independent variable. 
$2.5 \mathrm{msec}$ and were attenuated by Daven manual attenuators and by locally made programmable attenuators. Signals were amplified by Crown D60 amplifiers, and were presented over Telephonics TDH-39 headphones mounted in MX-41 cushions. All listeners were tested individually in a double-walled IAC chamber. The experiment was controlled by a Digital Equipment Corporation PDP-11/34 minicomputer.

\section{RESULTS}

The results are presented in Tables 2 and 3 , in units of proportion correct, in each of the observation intervals. The performance estimates for each interval shown in the body of Table 2 are based on approximately 400 trials; those in Table 3 are based on approximately 550 trials.

Table 2 shows performance for the 22 tasks collapsed over the 16 listeners. Performance was higher in interval 3 than in interval 1 for 19 of the 22 tasks (sign test, $\mathrm{p}<.001$; Anderson, 1966). Table 3 shows performance for the 16 listeners collapsed over 22 tasks. Performance was higher in interval 3 than in interval 1 for 14 of the 16 listeners (sign test, p < $.005)$. The mean overall difference between intervals 1 and 3 was approximately $8.5 \%$.

A repeated measures analysis of variance (Keppel, 1973) was run on the interval effects (16 listeners $x$ 22 tasks $=352$ interval effects). Statistically significant differences were found both among listeners $[\mathrm{F}(15,315)=5.00, \mathrm{p}<.001]$ and among tasks $[\mathrm{F}(21,315)$ $=2.00, p<.01]$. The tasks that showed the largest interval effects were the three tests of click-train duration discrimination, the three 200 -msec tests of frequency discrimination, and the detection thresholds for tones presented without external masking noise.

Thresholds for all histeners and tasks were transformed to $\mathrm{z}$ scores. These were summed across tasks to obtain an overall measure of each listener's threshold performance in z-score units. The rank order across listeners of these threshold performance data was correlated with the rank order across listeners of the mean magnitude of the interval effect, using the Spearman rank correlation statistic (Runyon \& Haber, 1977). The ranked magnitudes of the thresholds were significantly correlated with the ranked magnitudes of the interval effects $[\mathrm{r}(16)=$ $0.72, p<.01]$. That is, listeners with the lowest overall thresholds showed the smallest overall interval effects.

\section{DISCUSSION}

The results of this experiment show that performance does vary across the intervals for a wide variety of 3IFC tasks. ${ }^{3}$ Generally, performance is worst in interval 1 and best in interval 3 . In addition, there were statistically significant differences among the tests and the listeners in the magnitude of this interval effect. Within the context of signal detection theory there is no way in which these results can be attributed to varying criteria versus differential sensitivities across the three intervals.

These results, from an experiment employing 3IFC, disagree with the conclusions of Watkins and Clark (1968), who used a 4IFC task. Inspection of the data for the relevant conditions in their experiment, however, shows that performance for the final two intervals is superior to that of the first two intervals, by approximately $5 \%$. This difference is of approximately the same magnitude as the relevant condition of masked detection noted in our results above. So, to a first approximation, our results agree with the only other published research on the subject.

What causes the interval effect? It does not seem likely that this effect arises from backward masking of the stimulus in interval 1 by that presented in intervals 2 and 3 (Elliott, 1971; Moore, 1977, pp. 98-105), because most backward masking occurs within $100 \mathrm{msec}$ of masker onset and the intervals in these

Table 2

Proportion Correct per Interval for Tasks, Collapsed Over Listeners

\begin{tabular}{|c|c|c|c|c|c|c|c|c|c|c|c|c|c|c|c|c|c|c|c|c|c|c|}
\hline \multirow[b]{2}{*}{ Task } & \multicolumn{3}{|c|}{ MAT } & \multicolumn{2}{|c|}{ QAT } & \multicolumn{2}{|c|}{$\Delta \mathrm{I}$} & \multicolumn{4}{|c|}{$\Delta \mathrm{F}$} & \multicolumn{4}{|c|}{$\Delta \mathbf{T}$} & \multicolumn{3}{|c|}{ CLICK } & \multicolumn{2}{|c|}{ GAP } & \multicolumn{2}{|c|}{ SEQ } \\
\hline & 1 & 2 & 3 & 4 & 5 & 6 & 7 & 8 & 9 & 10 & 11 & 12 & 13 & 14 & 15 & 16 & 17 & 18 & 19 & 20 & 21 & 22 \\
\hline $\begin{array}{l}\text { Int. } 1 \\
\text { Int. } 2 \\
\text { Int. } 3\end{array}$ & $\begin{array}{l}.70 \\
.71 \\
.75\end{array}$ & $\begin{array}{l}.67 \\
.71 \\
.76\end{array}$ & $\begin{array}{l}.63 \\
.78 \\
.72\end{array}$ & $\begin{array}{l}.75 \\
.78 \\
.85\end{array}$ & $\begin{array}{l}.63 \\
.73 \\
.77\end{array}$ & $\begin{array}{l}.74 \\
.77 \\
.89\end{array}$ & $\begin{array}{l}.77 \\
.72 \\
.73\end{array}$ & $\begin{array}{l}.69 \\
.71 \\
.68\end{array}$ & $\begin{array}{l}.65 \\
.79 \\
.71\end{array}$ & $\begin{array}{l}.65 \\
.74 \\
.72\end{array}$ & $\begin{array}{l}.55 \\
.71 \\
.78\end{array}$ & $\begin{array}{l}.73 \\
.65 \\
.77\end{array}$ & $\begin{array}{l}.70 \\
.72 \\
.71\end{array}$ & $\begin{array}{l}.66 \\
.71 \\
.74\end{array}$ & $\begin{array}{l}.62 \\
.69 \\
.77\end{array}$ & $\begin{array}{l}.73 \\
.80 \\
.87\end{array}$ & $\begin{array}{l}.65 \\
.74 \\
.83\end{array}$ & $\begin{array}{l}.62 \\
.72 \\
.83\end{array}$ & $\begin{array}{l}.69 \\
.63 \\
.75\end{array}$ & $\begin{array}{l}.68 \\
.66 \\
.68\end{array}$ & $\begin{array}{l}.65 \\
.67 \\
.71\end{array}$ & $\begin{array}{l}.74 \\
.72 \\
.76\end{array}$ \\
\hline $3-1$ & .05 & .09 & .09 & .10 & .14 & .15 & -.04 & -.01 & .06 & .07 & .23 & .04 & .01 & .08 & .15 & .14 & .18 & .21 & .06 & .00 & .06 & .02 \\
\hline
\end{tabular}

Table 3

Proportion Correct per Interval for Listeners (L), Collapsed Over Tasks

\begin{tabular}{|c|c|c|c|c|c|c|c|c|c|c|c|c|c|c|c|c|}
\hline $\mathbf{L}$ & 1 & 2 & 3 & 4 & 5 & 6 & 7 & 8 & 9 & 10 & 11 & 12 & 13 & 14 & 15 & 16 \\
\hline $\begin{array}{l}\text { Int. } 1 \\
\text { Int. } 2 \\
\text { Int. } 3\end{array}$ & $\begin{array}{l}.68 \\
.68 \\
.76\end{array}$ & $\begin{array}{l}.72 \\
.70 \\
.80\end{array}$ & $\begin{array}{l}.70 \\
.68 \\
.75\end{array}$ & $\begin{array}{l}.62 \\
.68 \\
.80\end{array}$ & $\begin{array}{l}.73 \\
.78 \\
.75\end{array}$ & $\begin{array}{l}.70 \\
.75 \\
.75\end{array}$ & $\begin{array}{l}.64 \\
.72 \\
.85\end{array}$ & $\begin{array}{l}.71 \\
.79 \\
.72\end{array}$ & $\begin{array}{l}.72 \\
.72 \\
.78\end{array}$ & $\begin{array}{l}.67 \\
.72 \\
.78\end{array}$ & $\begin{array}{l}.65 \\
.74 \\
.81\end{array}$ & $\begin{array}{l}.75 \\
.73 \\
.72\end{array}$ & $\begin{array}{l}.69 \\
.73 \\
.76\end{array}$ & $\begin{array}{l}.74 \\
.73 \\
.72\end{array}$ & $\begin{array}{l}.42 \\
.61 \\
.75\end{array}$ & $\begin{array}{l}.68 \\
.78 \\
.71\end{array}$ \\
\hline $3-1$ & .08 & .08 & .05 & .18 & .02 & .05 & .21 & .01 & .06 & .11 & .16 & -.03 & .07 & -.02 & .33 & .03 \\
\hline
\end{tabular}


tests were 500 msec. Furthermore, the interval effect was observed in the case of the detection of tones in the absence of external masking noise. The cause of this effect should, it appears, be sought in the more "central" processes that limit selective attention, memory, or channel capacity. One method of testing this hypothesis is described in the Appendix.

The significance of the interval effect goes beyond the demonstration that the assumption of uniform performance among the intervals of a MIFC task is often wrong. Estimates of threshold obtained for specific tasks will be degraded in proportion to the magnitude of the interval effects, if, as seems likely, performance in the final interval is a valid index of sensitivity or resolving power. ${ }^{4}$ For example, the data described earlier from Watson et al. (1979) showed an overall percentage correct of 71 , whereas performance in interval 3 was $82 \%$. In the current study, those listeners who showed the largest overall interval effects also showed the poorest overall threshold values.

\section{REFERENCES}

Anderson, B. F. (1966). The psychology experiment. Belmont, CA: Brooks/Cole.

Creelman, C. D., \& Macmillan, N. A. (1979). Auditory phase and frequency discrimination: A comparison of nine procedures. Journal of Experimental Psychology: Human Performance \& Perception, 5, 146-156.

ElliotT, L. L. (1971). Backward and forward masking. Audiology, 10, 65-76.

Green, D. M., \& Swets, J. A. (1966). Signal detection theory and psychophysics. Huntington, NY: Krieger.

Jeste ADT, W., \& BilgeR, R. C. (1974). Intensity and frequency discrimination in one- and two-interval paradigms. Journal of the Acoustical Society of America, 55, 1266-1276.

Jeste ADT, W., \& Sims, S. L. (1975). Decision processes in frequency discrimination. Journal of the Acoustical Society of America, 57, 1161-1168.

Johnson, D. M., Jensen, J. K., \& Watson, C. S. (1980). Individual differences in auditory capabilities: A preliminary test battery. Journal of the Acoustical Society of America, 67, S58(A).

Johnson, D. M., Watson, C. S., \& Kelly, W. J. (1980). Interval biases in 3AFC experiments. Journal of the Acoustical Society of America, 68, S60(A).

KePPEL, G. (1973). Design and analysis: $A$ researcher's handbook. Englewood Cliffs, NJ: Prentice-Hall.

LEviTT, H. (1971). Transformed up-down methods in psychoacoustics. Journal of the Acoustical Society of America, 49, 467-477.

Moone, B. C. J. (1977). Introduction to the psychology of hearing. Baltimore, MD: University Park Press.

Runyon, R. P., \& Haber, A. (1977). Fundamentals of behavioral statistics. Reading, MA: Addison-Wesley.

Watkins, W. H., \& Clark, H. J. (1968). Forced-choice technique: Inter-alternative comparisons. Psychonomic Science, 11, 351-352.

Watson, C. S., Kelly, W. J., \& Mellen, D. M. (1979). Temporal and spectral determinants of informational masking in tonal patterns. Journal of the Acoustical Society of America, 66, S83(A).

Watson, C. S., Kelly, W. J., \& Wroton, H. W. (1976). Factors in the discrimination of tonal patterns. II. Selective atten- tion and learning under various levels of stimulus uncertainty. Journal of the Acoustical Society of America, 60, 1176-1186.

Yost, W. A., Turner, R., \& Bergert, B. (1974). Comparison among four psychophysical procedures used in lateralization. Perception \& Psychophysics, 15, 483-487.

\section{NOTES}

1. One approach to this problem might be to decompose the $\mathbf{M} \times \mathbf{M}$ matrix obtained in a MIFC task into yes-no, $2 \times 2$ confusion matrices, each of the form respond " $i$ " or "not $i$," for stimuli " $i$ " or "not $i$ ". This procedure would allow the calculation of values of $d$ ' and beta for each of the $M$ intervals. However, as a reviewer of an earlier version of this paper correctly pointed out, measures derived in this manner are not independent across the intervals and thus provide no means of unambiguously attributing the interval effects to differences in criterion versus differences in sensitivity.

2. Performance for interval 2 generally falls midway between that for intervals 1 and 3 , but seldom falls nearest to interval 1 .

3. We have since replicated the interval effect for frequency discrimination (Johnson, Watson, \& Kelly, 1980).

4. This caution is meant primarily for investigators employing MIFC procedures when $M$ is three or greater. We are aware that other considerations favor the use of 2IFC (Green \& Swets, 1966). In fact, in many types of listening tasks, performance obtained by 2IFC methods is better than that obtained with single-interval methods (Creelman \& Macmillan, 1979; Jesteadt \& Bilger, 1974; Jesteadt \& Sims, 1975; Yost, Turner, \& Bergert, 1974).

5. Sandler's A test is a simple-to-use statistic for the comparison of two correlated samples (Runyon \& Haber, 1977).

\section{APPENDIX}

One way to distinguish between central and peripheral origins of interval effects like those described in this paper is to eliminate the temporal uncertainty that is inherent in MIFC procedures. If the effect in some manner depends on the listener's nonuniform distribution of attentional resources across the $\mathrm{M}$ intervals, a procedure that eliminates the need for distributed attention might eliminate the effect. On the other hand, if the effect is "peripheral" in the sense that it is entirely determined by the manner in which the MIFC stimuli affect the sensory apparatus, then reducing the need for a temporal distribution of attention (or, equivalently, the need that detailed information from $M$ intervals be stored for later comparisons) should result in no change in the interval effect.

This central-peripheral hypothesis can be tested in a modified MIFC procedure in which the signal either occurs in a specific interval or does not occur at all. In other

Table A1

Mean $\Delta f$ (in Herz) and Standard Deviation for $71 \%$ Correct Decisions per Interval Collapsed Over Listeners

\begin{tabular}{cccccc}
\hline & \multicolumn{3}{c}{ Method } \\
\cline { 2 - 5 } & \multicolumn{2}{c}{$\begin{array}{c}\text { Minimal Uncertainty } \\
\text { 3-Stimulus }\end{array}$} & & \multicolumn{2}{c}{$\begin{array}{c}\text { Standard } \\
\text { 3IFC }\end{array}$} \\
\cline { 2 - 5 } Interval & Mean & SD & & Mean & SD \\
\hline 1 & 2.4 & 0.9 & 8.2 & 2.7 \\
3 & 3.7 & 1.0 & 3.0 & 1.2 \\
\hline
\end{tabular}

Note-Data are from two separate experiments: One used minimal uncertainty procedures, whereas the other used the standard 3IFC method. 
words, MIFC can be converted to a minimal-uncertainty psychophysical task (Watson et al., 1976) in which the stimuli that constitute the temporal context of the signal interval are constant from trial to trial.

A minimum-uncertainty, frequency-discrimination task was run in which, on each trial, the listener heard three 40msec, $550-\mathrm{Hz}$ tones. The listener was told that a specific one of the three tones would be incremented in frequency on a randomly chosen one-half of the trials. On the other half of the trials, the three tones were identical. (The method was thus like a "same-different" procedure but with two standard tones.) The tone that was subject to change was in the first temporal interval in one-half of the blocks of trials and in the third interval in the others. Listeners were told the temporal position of the tone that was subject to change. The size of the frequency increment was determined by an adaptive tracking algorithm that converged on the increment required to achieve $71 \%$ correct judgments. This particular discrimination task was chosen because it yielded the largest interval effects of any that we had examined. The results, shown in Table $\mathbf{A} 1$, indicated no significant difference in performance ( $\Delta \mathrm{f}$ for $71 \%$ correct decisions) between the first and third intervals [A test, $\mathbf{A}(3)$ $=0.42, p>.10] . .^{5}$ Performance on the same task is shown in the table for another group of listeners tested under the standard 3IFC procedure, for whom the usual interval effect was clearly present [A test, $A(2)=0.36, p<.05$ ].

Since the interstimulus interval in this particular task was set to an unusually small value (100 $\mathrm{msec})$, and because frequency discrimination for very brief tones is a task that is quite different from any of those reported in the preceding paper, this result does not permit general conclusions about the origins of the ubiquitous interval effects in MIFC procedures. This method of minimizing temporal uncertainty is an effective means, however, by which interval effects can be shown to be the result of central, rather than peripheral, factors in auditory processing.

(Manuscript received April 16, 1984; revision accepted for publication April 26, 1984.) 